Running head: Variability of Teachers' Technology Integration in the Classroom

\title{
Variability of Teachers' Technology Integration in the Classroom: \\ A Matter of Utility!
}

\author{
Iris Backfisch ${ }^{1,2}$, Andreas Lachner ${ }^{1,2}$, Kathleen Stürmer ${ }^{2}$, Katharina Scheiter ${ }^{1,2}$ \\ ${ }^{1}$ Leibniz-Institut für Wissensmedien, Tübingen, Germany \\ ${ }^{2}$ University of Tübingen, Germany
}

Date submitted: 27.03.2020

This article does not exactly replicate the final version published in Computers \& Education. It is not the copy of record.

Backfisch, I., Lachner, A., Stürmer, K., \& Scheiter, K. (2021). Variability of teachers' technology integration in the classroom: A matter of utility!. Computers \& Education, 166, 104159. https://doi.org/10.1016/j.compedu.2021.104159

Acknowledgement

We would like to thank Kathleen Preikschas for the support with programming the teacher diary and Anna Rosenträger for her assistance in conducting the study. Iris Backfisch is a doctoral student at the LEAD Graduate School \& Research Network [GSC1028], funded by the Excellence Initiative of the German federal and state governments. The research reported in this article was supported by the Federal Ministry of Education and Research in Germany (BMBF) under contract number 01JA1611. 


\begin{abstract}
Technology integration in the classroom is seen as a crucial factor to enhance teaching and learning processes. Whether and how technology affects student learning, depends on how teachers integrate technology into their classroom practice. To investigate technology integration, we used an experience sampling method with in-service teachers $(N=18)$. Over a period of six weeks, we assessed teachers' technology integration and technology-related motivation. By using a mixed-method approach, we found considerable variability of teacher motivation, frequency, and quality of technology integration across lessons. The variability could be explained by teachers' technology-related utility beliefs and specific factors within the different instructional contexts. The findings highlight the importance of teachers' utility and contextual aspects in their technology integration.
\end{abstract}

Keywords: educational technology, experience-sampling method, teaching quality, expectancy-value theory, technology integration 


\section{Introduction}

Researchers as well as politicians attribute educational technologies to have great potential in contributing to the quality of teaching and thus to the learning of students (Chauhan, 2017; Mayer, 2019; OECD, 2015; Zhu \& Urhahne, 2018). However, research shows that teachers tend to rarely use technologies and to exploit only to a limited extent the distinct potential technologies offer (Fraillon, Ainley, Schulz, Friedman, \& Duckworth, 2019). A critical boundary condition regarded to constrain technology integration is teacher motivation (Backfisch, Lachner, Hische, Loose, \& Scheiter, 2020; Petko, 2012; Taimalu \& Luik, 2019; Vongkulluksn, Xie, \& Bowman, 2018). Previous research reported positive associations between technology integration and teachers' self-efficacy to use technology in the classroom (e.g., Taimalu \& Luik, 2019). Simultaneously, recent studies documented that the anticipated utility of technology for teaching purposes was related to the quantity and quality of technology integration (e.g., Backfisch et al., 2020). However, most previous research was cross-sectional, which has not allowed to investigate the variability and reciprocal relationships between teacher motivation and technology integration. Answering these research questions constitutes an important research avenue, as previous research documented that teacher motivation and teaching quality highly fluctuate across lessons and as such largely depend on the particular instructional context in which technology is applied (Praetorius, Pauli, Reusser, Rakoczy, \& Klieme, 2014; Seidel \& Prenzel, 2006; Turner \& Meyer, 2000).

Against this background, in the current study, we investigated 1) whether and how teacher motivation and technology integration vary across lessons, 2) examined relationships between teacher motivation and quantity and quality of technology integration across lessons, and additionally, 3) explored the contextual factors which affected variations in teacher motivation and technology integration. To investigate these research questions, we conducted 
an experience sampling study (Endedijk, Brekelmans, Verloop, Sleegers, \& Vermunt, 2014), in which we systematically traced trajectories of in-service teacher motivation and the quantity and quality of technology integration over a period of six weeks by means of a webbased teacher-diary. In this teacher-diary, teachers weekly rated their current motivation (i.e., their perceived utility-value and self-efficacy of teaching with technology) and documented one technology-based lesson per week. The resulting data were analyzed by applying a mixed-method approach (McCrudden, Marchand, \& Schutz, 2019) aiming at identifying trajectories and reciprocal relations of teacher motivation and the quantity and quality of technology integration. First, quantitative analysis by means of variance component analysis and growth-curve models allowed us to identify potential systematic variations and relations of teacher motivation and technology integration. Second, qualitative analyses by means of criterion-based sampling approaches allowed us to reconstruct potential contextual determinants that affected variability of teacher motivation and technology integration.

\subsection{Technology Integration into Classroom Practice}

Integrating technologies into teaching can be regarded as one of the crucial endeavors to support students' learning and enable them to participate in a digitalized society (OECD, 2015; U.S Department of Education, 2020). In the context of teaching, technology integration commonly refers to teachers' adoption of educational technologies during classroom teaching,

such as the use of distinct hardware (e.g., mobile technology, tablets; see Beauchamp, Burden, \& Abbinett, 2015), or software applications (e.g., tools, see Krauskopf, Zahn, \& Hesse, 2012) to realize specific teaching processes (Danniels, Pyle, \& DeLuca, 2020; Dukuzumuremyi \& Siklander, 2018; Näykki, \& Järvelä, 2008; Paratore, O’Brien, Jimenez, Salinas, \& Ly, 2016). Technology integration can be conceptualized on the quantitative and the qualitative level. On the quantitative level, technology integration commonly refers to the mere frequency of technology integration, which is, for instance, determined by simply counting how often a 
particular technology was used during classroom teaching (e.g., Fraillon, Ainley, Schulz, Friedman, \& Gebhardt, 2014). These quantity indicators give an overview regarding the general level of technology usage in schools, however, they do not cover in-depth qualitative aspects of technology integration which are presumably crucial for the effectiveness of technology integration (e.g., enhance teaching quality; OECD, 2015).

Following Backfisch et al. (2020), the quality of technology integration can be operationalized on two different dimensions: First, the level of technology exploitation refers to teachers' capability to implement the distinct potential of educational technologies to scaffold students' learning (Endberg, 2019; Hamilton, Rosenberg, \& Akcaoglu, 2016). The most prominent models describing different hierarchical levels of technology exploitation are the SAMR-model (acronym for substitution, augmentation, modification, redefinition, see Puentedura, 2006) and the RAT-model (acronym for replacement, amplification, transformation by Hughes, Thomas, \& Scharber, 2006). Both models comprise distinct levels of technology integration: at the lowest level, technologies are used to substitute or replace traditional technologies (e.g., reading a digital pdf document instead of reading a printed book). At the intermediate level, technology integration helps realizing more efficient teaching methods and serves to augment traditional teaching methods (e.g., using a livesynchronized collaborative digital whiteboard). At the highest level, the use of technology may allow teachers to redefine or transform current teaching methods which would not be possible without technology integration, such as providing multi-media information (Moreno \& Mayer, 2007; Renkl \& Scheiter, 2017) or adaptive support (e.g., Lachner, Burkhart, \& Nückles, 2017; Ma, Adesope, Nesbit, \& Liu, 2014; Zhu \& Urhahne, 2018). Nevertheless, such models only focus on the types of technology use and ignore the potential impact on learning processes (Hamilton et al., 2016) and more precisely the impact on teaching quality (Backfisch et al., 2020). Although there is a broad range of models conceptualizing teaching 
quality (Brophy, 1999; Eccles \& Roeser, 2009; Hamre \& Pianta, 2007; Pianta \& Hamre, 2009), there is consensus that teaching quality can be described with respect to the taskspecific strategies, which is cognitive activation and individual learning support, and the taskgeneral strategies, such as classroom management (Baumert et al., 2010; Fauth, Decristan, Rieser, Klieme, \& Büttner, 2014; Hugener et al., 2009; Kunter et al., 2013; Praetorius, Klieme, Herbert, \& Pinger, 2018). Cognitive activation refers to task-specific instructional strategies which trigger students' cognitive engagement during learning, for instance, by providing them with challenging tasks, the exploration of concepts, and the activation of prior knowledge. These instructional strategies should contribute to students' deep processing during learning and, in turn, support their content-related understanding (Fauth et al., 2014; Kunter et al., 2013). Individual learning support covers instructional strategies which aim at scaffolding task-specific learning processes and knowledge construction (Kunter et al., 2013). Consequently, such support strategies are characterized by forms of student-centered and adaptive teaching (van de Pol, Volman, Oort, \& Beishuizen, 2015), such as monitoring students' learning process, providing personalized feedback, and contiguous adaptions of teaching (Kunter et al., 2013; van de Pol et al., 2015). Classroom management is a taskgeneral aspect of teaching quality and refers to generic strategies that focus on establishing and maintaining the smoothness of teaching such as coping with potential disruptions during a lesson (Fauth et al., 2014; Kounin, 1970; Kunter et al., 2013). Commonly, it is assumed that technology can have an effect on task-specific aspects of teaching quality (i.e., cognitive activation, individual learning support) because it has the potential to implement demanding learning tasks and cognitively engaging learning environments (e.g., virtual simulations), and at the same time provide students with adequate individual learning support (e.g., adaptive feedback). However, it is an open question whether and how technology integration affects 
task-general aspects of teaching quality such as the smoothness of the lesson as there is a lack of research in this regard.

\subsection{Motivation as Boundary Condition for Technology Integration}

Recent research has identified several boundary conditions that constrain the quantity and quality of technology integration, such as the availability of technological infrastructure (Drossel, Eickelmann, \& Gerick, 2017; Fraillon et al., 2014; Petko, 2012) and the level of teachers' professional knowledge (cf. technological-pedagogical content knowledge, Lachner, Backfisch, \& Stürmer, 2019; Mishra \& Koehler, 2006). More importantly, recent research has emphasized the crucial role of teacher motivation as a further boundary condition of technology integration (e.g., Backfisch et al., 2020; Cheng \& Xie, 2018; Ifenthaler \& Schweinbenz, 2013; Petko, 2012; Scherer, Siddiq, \& Tondeur, 2019; Scherer \& Teo, 2019; Teo, 2011; Taimalu \& Luik, 2019; Vongkulluksn et al., 2018). For instance, the technologyacceptance model (TAM, see Scherer et al., 2019; Teo, 2011) describes whether and how teachers' acceptance and use of technologies depend on their motivation (see Scherer \& Teo, 2019; Teo, 2011).

Scherer et al. (2019) aggregated findings from 114 questionnaire studies $(N=34,577$ teachers) which used the TAM as theoretical framework and investigated the relation between teacher motivation (i.e., perceived usefulness of educational technologies, self-efficacy of using educational technologies) and their intention and frequency to use technologies for teaching. The authors found that self-efficacy and perceived usefulness largely predicted teachers' intention to use technology. Moreover, higher levels of behavioral intentions yielded higher degrees of technology integration (see also Scherer \& Teo, 2019; Wozney, Venkatesh, \& Abrami, 2006). From a psychological perspective, these findings can be interpreted in terms of expectancy-value theory (Eccles \& Wigfield, 2002), which has gained considerable popularity in teacher education in recent years (e.g., Cheng \& Xie, 2018; Green, 2002; 
Wozney et al., 2006). Expectancy-value theories claim that the successful realization of a task is largely related to the individual expectancies toward successfully accomplishing a certain task (cf. self-efficacy, Bandura, 2010) and the associated individual value of the task (cf. utility-value, Eccles \& Wigfield, 2002). Furthermore, expectancy-value theories not only consider the quantity, but also highlight the quality of how teachers successfully accomplish actions as the result of their self-efficacy and perceived utility-value (e.g., expectancy-value theory of achievement-related choices and performance; Eccles \& Roeser, 2009, 2011). Therefore, the quality of technology integration during teaching might be influenced by selfefficacy of using technologies for teaching and perceived utility-value of educational technologies for teaching and learning processes. In this context, expectancy-value theory goes beyond specific technology-acceptance models (Teo, 2011), as it also presumes differences in the quality of distinct tasks such as technology integration and not only in the quantity or frequency of technology use.

One of the first studies examining the effects of teacher motivation (i.e., self-efficacy, utility-value) on the quality of technology integration is the study by Backfisch et al. (2020). In a relative expertise study, the authors asked teachers to answer a test measuring their professional knowledge and report their self-efficacy and utility-value regarding technology use. Additionally, the participants provided a worked-out lesson plan on the introduction of the Pythagorean theorem. The authors found that teachers with higher levels of expertise (i.e., trainee teachers, in-service teachers) were more capable of integrating technology, as they provided lesson plans involving methods of higher instructional quality and greater technology exploitation than novice teachers. The effect of teacher expertise on the quality of the lesson plans could be explained by the perceived utility-value of technology integration, but not by self-efficacy regarding using technology. Surprisingly, professional knowledge did not mediate the effect of teacher expertise on the quality of technology integration either, indicating that 
predominantly motivation accounted for the quality of technology integration (Backfisch et al., 2020).

These findings emphasize the importance of teachers' utility-value regarding their technology integration. Despite the valuable findings, however, it has to be noted that the study by Backfisch et al. (2020) was cross-sectional and conducted in a controlled but relatively artificial setting, as it only described teachers' potential technology integration by means of a scenario approach regarding one teaching task at one point in time. Thus, it is unclear whether the findings by Backfisch et al. would replicate in more applied settings in which teachers were required to actually implement technology over a course of various lessons.

\subsection{Variability of Technology Integration and Motivation across Lessons}

There is considerable empirical evidence that the quality of (technology-based) lessons substantially varies across different teachers, but also across individual teachers' lessons (Praetorius et al., 2014; Seidel \& Prenzel, 2006). Praetorius et al. (2014) investigated the stability of teaching quality across lessons. By applying variance component analysis, the authors were able to identify stable and varying components of teaching quality measured by observer ratings. Whereas classroom management and individual learning support remained relatively stable across lessons, cognitive activation varied largely across lessons. This variability across lessons indicates that teaching quality is constrained by different instructional contexts. Instructional context encompasses all factors which affect the processes in the classroom (Turner \& Meyer, 2000) such as differences in subject-matter content which potentially affect the teaching methods used (see Fauth et al., 2019; Praetorius et al., 2014) but also different levels of teacher and student motivation which potentially influence the smoothness of the lesson and learning outcome of students (Kunter et al., 2013). 
This assumption is in line with recent motivational theories (Eccles, 2005; Hidi \& Harackiewicz, 2000), which highlight that motivational beliefs depend on distinct aspects of the task to be accomplished and contextual aspects determining the distinct tasks. Therefore, teacher motivation might vary across lessons (Holzberger, Philipp, \& Kunter, 2013; Praetorius et al., 2017).

\subsection{The Present Study: Variability and Relation of Motivation and Technology Integration}

We aimed at investigating potential relations of teachers' motivation (i.e., self-efficacy, utility-value) and the quantity and quality of technology integration across lessons. Therefore, we followed an experience sampling approach in which teachers regularly wrote entries in a web-based teacher-diary over a period of six weeks (for related approaches see Wäschle, Allgaier, Lachner, Fink, \& Nückles, 2014). In each entry, teachers documented their lessons and reported their current self-efficacy and perceived utility-value regarding technology integration. Such experience sampling approaches are often applied within professional settings, like medicine or teacher education, as they do not interfere with daily professional practices (e.g., teaching), and as such, have been shown to be valid instruments to trace trajectories of professional behaviour and its underlying inter-individual constituents (e.g., Endedijk et al., 2014; Könings et al., 2016; Wäschle et al., 2014). The rich data provided within the lesson documentations allowed us to follow a mixed-method approach by applying quantitative and qualitative analysis of the lesson documentations.

\subsubsection{Research questions}

Following the current debate within motivational research, we investigated whether technology-related self-efficacy and perceived utility-value beliefs vary (i.e., are state variables) or remain stable across lessons (i.e., are trait variables). Therefore, we investigated the variability and differences of motivation across entries: 
Research question 1: Do teachers' intra-individual technology-related self-efficacy $(R Q 1 a)$ and utility-value $(R Q 1 b)$ vary or remain stable across entries in the teacher-diary?

Second, based on general findings of teaching quality (Praetorius et al., 2018), we also investigated potential variability of the quantity (i.e., $R Q 2 a$ frequency of technology integration) and quality of technology integration (i.e., $R Q 2 b$ technology exploitation and teaching quality).

Research question 2: Does the quantity ( $R Q 2 a$ frequency) and quality ( $R Q 2 b$ technology exploitation, task-specific and task-general teaching quality) of technology integration vary or remain stable across entries in the teacher-diary?

More importantly, we were interested in potential relations between teacher motivation (i.e., self-efficacy and utility-value) and the quantity and quality of their technology integration. Therefore, we examined whether intra-individual technology-related self-efficacy and utility-value beliefs accounted for the quantity (i.e., frequency of technology use $R Q 3 a$ ) and quality of technology integration across entries (i.e., $R Q 3 b$ technology exploitation and teaching quality).

Research question 3: Does the individual level of self-efficacy and utility-value predict the quantity ( $R Q 3 a$ frequency) and quality $(R Q 3 b$ technology exploitation and taskspecific and task-general teaching quality) of technology integration?

To investigate our research questions, we followed a mixed-method approach (McCrudden et al., 2019): We used quantitative analyses to investigate the variability of technology integration and teacher motivation, and to trace potential relations of these key constructs across lessons, by applying recently applied methods such as variance component 
analysis (see Mantzicopoulos, French, Patrick, Watson, \& Ahn, 2018; Praetorius et al., 2018) and linear mixed effect models (Duckworth, Tsukayama, \& May, 2010). These quantitative analyses were accompanied by qualitative analyses to investigate potential accounts of the instructional contexts, which may have evoked potential intra-individual variability. We followed a criterion-based sampling approach and selected prototypical cases of the lesson documentations to reconstruct potential contextual determinants (White, DeCuir-Gunby, \& Kim, 2019).

\section{Method}

\subsection{Research Context}

The current study was conducted within the context of an initiative of the ministry of education of a federal state in Germany. Within this initiative, 28 classes from seventh grade secondary academic track were equipped with mobile technology (i.e., tablets) and infrastructure (i.e., internet access). During the initiative, the teachers were asked to integrate technologies into their daily classroom practices. However, the teachers were not enrolled in professional development programs; rather, they had to adopt technologies into their teaching without any further support. The study was conducted in the beginning of the initiative. Thus, the research context allowed us to investigate potential trajectories and relationships of teacher motivation and technology integration in the context of beginning technology implementation under real conditions with high ecological validity.

\subsection{Participating Teachers}

All the teachers of the initiative were invited to participate in the study via the school coordinators, who were regular teachers at schools but additional local contact persons for the initiative. Sixty-seven teachers originally agreed to participate in the study. However, given that the study was conducted on top of the regular teaching tasks (full-time), a large proportion of teachers only made one or two entries $(n=49)$. The limited amount of entries, 
therefore, did not allow to investigate the variability of teacher motivation and its impact on technology integration. Therefore, we decided to select only data from teachers who provided at least three entries across the six weeks. This procedure resulted in a sample of $n=18$ teachers comprising 83 entries $(M=4.61$ entries per teacher on average, $S D=.78)$.

The teachers were teaching in seventh grade academic track in German secondary schools. They were comparably distributed across different subjects (i.e., German, English as a foreign language, Mathematics, and History). The teachers had on average 14 years $(S D=7.91)$ of teaching experience and were 42 years old on average $(S D=8.55)$; nine teachers were female. All teachers were fully certified and had successfully graduated from the study phase of a university teacher education program (approx. 5 years of studies) and the mandatory and structured induction phase (approx. 2 years). At the time of their training, teaching with technologies had not been a mandatory part of German teacher education.

2.2.1 Systematic analysis of included and excluded teachers. As the selection procedure could have resulted in biased data (e.g., inclusion of very motivated teachers), we ran a set of $\chi^{2}$ - and $t$-tests on critical confounding variables to ensure the validity of our findings. Thus, we compared the included teachers of the current study to the remaining teachers of the initiative. Note, that such comparisons with the larger reference group were possible by reanalyzing secondary data of the main initiative (see http://tablet-tuebingen.de/). None of the statistical tests approached statistical significance: The teachers of the current study did not differ from the overall teacher sample ${ }^{1}$ regarding their gender, $\chi^{2}(1)=0.17, p=$ .794 ; age, $t(90)=-1.83, p=.071$, and teaching experience, $t(90)=-1.61, p=.112$.

Furthermore, the teachers' perceived utility-value, $t(88)=.49, p=.655$, and their self-

\footnotetext{
${ }^{1}$ Note: The degrees of freedom vary because of missing data within the different scales in the main sample.
} 
efficacy, $t(86)=-1.42, p=.159$ were comparable to the main sample of the tabletBW study (see chapter 3.1 for the descriptive statistics).

\subsection{Design}

We followed an experience sampling approach over a period of six weeks with a newly developed web-based teacher-diary. Teachers were required to make one entry into the teacher-diary per week (i.e., documentation of one lesson, self-efficacy, and utility-value). The dependent variables encompassed the quantity of technology integration (i.e., frequency of technology integration, type of technology integration), as well as the quality of technology integration (i.e., technology exploitation and teaching quality) of the documented lessons per entry. As predictors, we used teachers' technology-related self-efficacy and perceived utilityvalue per entry.

\subsection{The Teacher-Diary}

The web-based teacher-diary was implemented in questback.de (Questback, 2017). The teacher-diary was piloted with six teachers from the initiative tabletBW to determine the feasibility and technical implementation. Based on feedback of the teachers, we reduced the scales and re-formulated some of the instructions. None of the teachers who took part in the pilot phase participated in the current study.

2.4.1 Motivation section. Based on expectancy-value theory (Eccles \& Wigfield, 2002), we assessed teachers' technology-related self-efficacy and their perceived utility-value regarding the use of technology for teaching as critical motivational states of technology integration.

2.4.1.1 Technology-related self-efficacy. To assess teachers' self-efficacy regarding the use of technology for teaching, we used four adapted items by Rigotti, Schyns, and Mohr (2008; e.g., "In this week, I was able to cope with the demands of technology-enhanced teaching."; "In this week, I was able to use technology to encourage the learning of the 
students.”). The teachers rated the items on a 4-point Likert scale from 1 (strongly disagree) to 4 (strongly agree). The reliability of the scale was good, Cronbach's $\alpha=.843$.

2.4.1.2 Utility-value. We applied two adapted items from van Braak, Tondeur, and Valcke (2004; i.e., "In this week, I thought technologies were useful for my lessons.”; "In this week, I really appreciated the added value of introducing technology into the classroom.", see also Backfisch et al., 2020; Sang, Valcke, van Braak, \& Tondeur, 2010; Teo, Huang, \& Hoi, 2018). Again, the teachers rated their perceived utility on a 4-point Likert scale from 1 (strongly disagree) to 4 (strongly agree). The reliability of the scale was good, Cronbach's $\alpha$ $=.846$.

2.4.2 Lesson documentation section. To examine the quantity of technology integration, teachers were asked to indicate how many lessons they taught this week in total and how often they used technologies ("I taught _ lessons this week and used technologies in _ lessons").

To obtain insights into the quality of technology integration, the teachers were asked to document one prototypical technology-based lesson that had been exemplary for the particular week by means of an open question. To guide teachers in the documentation of the lesson, they received a set of prompts (e.g., "What were the central teaching objectives of the lesson?", "Which instructional method did you use?", "How did you use educational technology during teaching?", "Did the educational technology assist you to achieve your teaching objectives, and if so, how?” see Backfisch et al., 2020; Kramarski, \& Michalsky, 2010, for related approaches). The lesson documentations encompassed on average 110 words $(S D=81)$ and were used to a) code the type of technology usage as a further proxy for the quantity of technology integration, and b) rate the quality of technology integration.

Additionally, teachers were asked to rate the smoothness (Kounin, 1970) of their technology integration within the described lesson on a 5- point Likert scale from 1 (does not 
apply) to 5 (does apply), as a proxy for the task-general teaching quality while using technology (i.e., "In this week, the technology integration worked smoothly.").

\subsection{Analysis and Coding}

\subsubsection{Quantity of technology integration.}

2.5.1.1 Frequency of technology integration. Based on the information of lessons taught in total and lessons taught with technologies, we calculated the proportion of technology integration for each week.

2.5.1.2 Type of technology integration. We analyzed the different applications of educational technologies that teachers described in their lesson documentations and summarized them using an inductive categorization process (Mayring, 2015). This resulted in nine dominant types of educational technologies (Backfisch et al., 2020). The interrater agreement between the two raters for $39 \%$ of the lesson plans was good with $87 \%$ of the total agreement $($ Kappa $=.57)$. Please note that Cohen's $\kappa$ is less accurate when there are large variations between the overall occurrences of categories and therefore a difference between Cohen's $\kappa$ and the exact agreement occurred (Wirtz \& Caspar, 2002).

\subsubsection{Quality of technology integration.}

2.5.2.1 Technology exploitation. To assess whether teachers were able to exploit the distinct functions of technologies, we analyzed the quality of technology exploitation within the documented lessons. We provided four subcategories to specify the judgements, see Table 1. These categories encompassed the level of innovativeness of technology adoption within the lesson based on the hierarchical framework by Hughes et al., (2006), as well as the level of exploitation of distinct affordances of technology integration based on research on technology-enhanced learning. For each category, the teachers could receive 0 (i.e., subcategory not applied) to 3 points (i.e., subcategory ubiquitously applied), yielding a possible maximum score of 12 . Two trained raters coded $20 \%$ of the lesson documentations. 
Interrater reliability was very good, ICC $(2,1)=.81$ (Koo \& Li, 2016; Wirtz \& Caspar, 2002). Thus, only one rater coded the remaining lesson documentations.

*Insert Table 1 about here*

2.5.2.2 Teaching quality. The teaching quality was assessed with respect to task-specific and task-general strategies. The task-specific teaching quality of the documented lessons was rated on the dimensions of cognitive activation and individual learning support. The raters had four subcategories available to specify their judgments, see Table 1 (adapted from Backfisch et al., 2020; Hugener et al., 2009; Kunter et al., 2013; Praetorius et al., 2018). For each subcategory, the teachers could receive 0 (i.e., subcategory not applied) to 3 points (i.e., subcategory ubiquitously applied), yielding a possible maximum score of 12 . To determine the reliability of our categorization, again, two trained raters coded $20 \%$ of the lesson documentations. Interrater agreement was very good, $\operatorname{ICC}(2,1)=.92$. Thus, only one rater coded the remaining lesson documentations. Additionally, as a proxy for the task-general teaching quality (i.e., classroom management), we used teachers' self-ratings of the smoothness item, as documentations likely are less capable to measure teachers' classroom practices and research showed that teachers' are capable to assess their classroom management (Aldrup, Klusmann, Lüdtke, Göllner, \& Trautwein, 2018; Wagner et al., 2016).

\subsection{Quantitative Analysis}

2.6.1 Variability of the measures. To investigate whether teacher motivation varied, we followed suggestions by Praetorius et al. (2018) and applied variance component analysis with the help of generalizability theory (cf. G theory). Variance component analysis allows the separation of different factors (i.e., variance components) which determine a distinct measure. Therefore, variance explained by intra-individual or inter-individual differences, and residual variance can be identified (Praetorius, Lenske, \& Helmke, 2012; Praetorius, Vieluf, Saß, Bernholt, \& Klieme, 2016). By applying variance component analysis based on G theory 
within the framework of multilevel analysis, the analysis accounts for the nested structure of longitudinal data (i.e., measuring points / entries nested within teachers). Therefore, in the current study, variance components can be separated which are due to differences between the teachers (i.e., variance explained by the teacher), differences across lessons (i.e., variance explained by the different lessons of one teacher), and unexplained variance. When distinct analyses show high proportions of residual variance, they indicate that a large proportion likely emerges due to other prevailing contextual differences which are not captured in the mathematical model. We applied the gtheory package (Moore, 2016) implemented in the lme4 package (Bates, Maechler, Bolker, \& Walker, 2015) within R Studio (R Core Team, 2019).

2.6.2 Relation of motivation and technology integration. To investigate the relations of self-efficacy and utility-value and the quantity and quality of technology integration we applied growth-curve models. Growth curve models are a special case of linear mixed effects models to account for the nested data structure, as measurement points were nested within persons (Duckworth et al., 2010). Growth curve models enable to analyse "inter-individual variability in intra-individual patterns of change over time" (Curran, Obeidat, \& Losardo, p. 2). Within these models, each teacher served as her or his individual baseline measure (i.e., intercept) and the change (i.e., slope) from one measuring point to the subsequent measuring point was analyzed. The models considered the entries (i.e., different measurement points over time) to be nested within teachers, so 'entries' represented Level 1 and 'teachers' represented Level 2. The dependent variables comprised the measures for quantity and quality of technology integration (i.e., frequency, technology exploitation, task-specific and taskgeneral teaching quality). Entries (as dummy-coded variable representing the different measuring points over time), self-efficacy and utility-value were included as predictors. For each dependent variable, the (unstandardized) estimates, standard error and 95\% confidence interval $(C I)$ are reported. If the $95 \%$ CI did not encompass zero, the distinct predictor can be 
interpreted as being significant. We applied the lmer command of the lme 4 package (Bates et al., 2015) of R Studio (R Core Team, 2019).

\subsection{Qualitative Analysis}

The main aim of the qualitative analysis was to understand which contextual factors accounted for the potential variability of teacher motivation and their technology integration across entries. Therefore, the analysis unit of the qualitative investigations was the openended lesson documentation section. We followed a criterion-based sampling approach, and purposefully selected representative cases of teachers (regarding variability, motivation, and technology integration; see White et al., 2019 for related approaches). Additionally, we took care of equally representing teachers' demographics. We followed the approach of qualitative content analysis (Cho \& Lee, 2014; Mayring, 2015): First, we segmented the lesson documentations of each teacher in instructional units and generalized each unit to a more abstract level with special focus on the particular technology integration, content taught, pedagogical approach and important contextual factors. Second, commonalities and differences between the different units across lessons of one teacher were identified and generalized on an abstract level. Based on this abstraction, we identified two lessons of each teacher with the largest discrepancies in their technology integration. Finally, commonalities and differences between the selected lessons across teachers were identified and conclusions were derived. To refine our analysis and ensure the rigor of our qualitative analysis, each step and especially the conclusions were discussed among the authors.

\subsection{Procedure}

We informed the teachers that the scope of the study was to learn more about their technology integration and potential boundary conditions during teaching with technology. All the teachers provided written consent to participate in the study. We obtained ethical approval from the Ministry of Education, Culture, Youth and Sports of regional state. The link 
to the teacher-diary was sent via email. At the first log-in, the teachers provided information on their demographic data (i.e., age, gender). Afterwards, they were asked to provide one entry with one lesson documentation per week over a period of six weeks. One entry lasted approximately 15 minutes. At the end of the study, the teachers received a computer-based report about the central trajectories of their motivation, their technology application, and the self-assessed quality of technology-enhanced lessons as compensation.

\section{Quantitative Findings}

\subsection{Preliminary Explorative Analyses}

For the descriptives of the measured constructs across all measurement points and for bivariate cross-sectional correlations between the general means of the different constructs across lessons see Table 2 and Table 3.

*Insert Table 2 about here*

*Insert Table 3 about here*

The analysis of the types of technology usage indicated that teachers most frequently used generic technologies, such as presentation tools (e.g., keynote, PowerPoint), e-text readers (e.g., e-books, pdf-documents), exercise software or file transfer services (e.g., airdrop, cloud services), see Figure 1. However, teachers rarely used subject-specific tools, such as virtual simulations (e.g., GeoGebra), or formative assessment technologies, such as audience response systems (e.g., kahoot, socrative).

*Insert Figure 1 about here*

\subsection{RQ1: Intra-individual Variability of Motivation}

To investigate the intra-individual variability of self-efficacy (RQ1a) and utility-value (RQ1b) across entries, we used variance component analysis to identify the variance explained by systematic differences between teachers, across lessons and unexplained variance, see Figure 2. We found that a considerable amount of variance of teachers' self- 
efficacy and utility-value could be explained by stable teacher traits $(V C>27 \%)$. The amount of variance explained by systematic differences during the course of lessons was relatively low $(V C<6 \%)$. Most of the variability of teacher motivation was unexplained variance.

These findings suggest that besides distinct motivational traits, a large proportion of variance likely emerged due to differences in instructional contexts.

*Insert Figure 2 about here*

\subsection{RQ2: Variability of Quantity and Quality of Technology integration.}

To investigate the variability of the quantity (RQ2a) and quality of technology integration (RQ2b), we again applied variance component analysis (see Figure 3). We found low amounts of explained variance by teacher traits for the frequency of technology integration and the task-specific indicators of teaching quality (i.e., cognitive activation and individual learning support, $V C<11 \%$ ). For the smoothness of the lessons, as a task-general indicator of teaching quality, the amount of variance explained by the teachers $(V C=25 \%)$ was considerably larger, suggesting that a significant proportion of the task-general teaching quality could be explained by relatively stable teacher traits. Again, only a small amount of variance could be explained by systematic differences between the lessons (ranging from 1$5 \%$ ), and the highest variance component remained unexplained variance (70-88\%). Overall, the high residual variance across our measures of the quantity and quality of technology integration demonstrated that most of the variability was not explained by systematic teacher traits or general time course, but highly depended on contextual factors emerging from the particular teaching environment.

*Insert Figure 3 about here*

\subsection{RQ3: Motivation and Technology integration.}

We analyzed systematic links of motivational states (i.e., self-efficacy, utility-value) and the technology integration by applying linear mixed effect models. The analysis indicated that 
self-efficacy was not related to the frequency of technology integration (RQ3a),

Estimate $=-.880, S E=4.914,95 \% C I[-10.510,8.752]$, as zero was not included in the confidence interval, however, utility-value was, Estimate $=7.910, S E=3.896,95 \%$ CI $[0.273$, 15.547]. This finding indicates that the quantity of technology integration was related to the perceived utility-value of technology.

A similar pattern emerged for the quality of technology integration (RQ3b): Self-efficacy was neither related to technology exploitation, Estimate $=-0.112, S E=0.131,95 \% C I[-$ $0.370,0.145]$, nor to task-specific teaching quality, Estimate $=-0.027, S E=0.088,95 \% C I[-$ 0.201, 0.146]. However, again, utility-value was related to technology-exploitation, Estimate $=0.367, S E=0.325,95 \% C I[0.161,0.573]$, and task-specific teaching quality, Estimate $=$ $0.189, S E=0.070,95 \% C I[0.050,0.327]$. Interestingly, both utility-value and self-efficacy predicted the task-general teaching quality (i.e., smoothness of technology integration): selfefficacy, Estimate $=0.448, S E=0.165,95 \% C I[0.124,0.771]$; utility-value, Estimate $=$ $0.417, S E=0.128,95 \% C I[0.166,0.669]$. This finding indicates that besides the perceived utility, self-efficacy was strongly linked to maintaining high levels of classroom management in technology-based teaching environments.

Overall, the quantitative findings suggest that teacher motivation and teaching quality can be regarded as variable states which are likely constrained by individual characteristics emerging from differences of the particular instructional context. Additionally, the individual level of perceived utility was significantly linked to the quantity and quality of technology integration.

\section{Qualitative Analysis}

The primary goal of the qualitative analysis was to understand potential characteristics and constituents of the variability of utility-value and its relationship to the quality of technology integration. Therefore, we identified prototypical teachers: Klaus (44 years old, 
history teacher), Patrick (30 years old, mathematics teacher), and Anna (48 years old, English as Foreign Language teacher), see Figure 4 and Figure 5 for their trajectories of motivation and technology integration.

\author{
*Insert Figure 4 about here* \\ *Insert Figure 5 about here*
}

\title{
4.1 Klaus: An example in History Teaching.
}

Klaus was a history teacher with 13 years of working experience who judged himself as novice in technology integration. He showed reasonable variability of utility-value and variability of technology integration over time. In his first documented lesson, he showed low levels of utility-value. In this lesson, he planned a learning activity which aimed at fostering students' critical thinking about the potential consequences of the early European exploration in the $15^{\text {th }}$ century. To achieve these goals, he implemented a Padlet (a live-synchronized whiteboard application to initiate collaborative learning activities) but had to stop the learning activity:

The formation of judgement should be supported by joint exchange using a Padlet. Two problems led me to break this off after a few minutes: 1) Apart from a few exceptions, the posts were extremely superficial, so that no process of judgement formation was recognizable. 2) (...) This was abused by a student to an offensive post about a not present classmate. (Klaus, entry week 1)

This documentation may be indicative that the given instruction during the collaborative learning activity was not clear enough, which resulted in the superficial judgments. Furthermore, the low levels of classroom management resulted in an offensive post by a student. Klaus proceeded as follows:

Second, we prepared a panel discussion. One student suggested to film the subsequent panel discussion. I spontaneously agreed on that, however, the filming did disturb the 
students' discussion. Therefore, I stopped the filming and the students proceeded with the discussion. (Klaus, entry week 1)

The spontaneous addition of recording resulted in additional disturbances during the discussion, which likely decreased the general teaching quality of the lesson. Together, week one illustrates that Klaus' lack of preparation regarding technology integration and the resulting students' disturbances likely determined the low levels of perceived utility-value and quality of technology integration. Therefore, Klaus' utility-value and quality of technology integration likely mutually dependent.

In the fourth week, Klaus perceived high utility-value. In his lesson, he dealt with the German Peasants War. He used the mBook which is a digital textbook that comprised digital learning activities, based on multiple-source comprehension: "First, I showed a picture, then students worked out the connections of the Memminger declaration and Reformation with the help of different texts in the mBook, and worked on tasks provided within the book." (Klaus, entry week 4)

Relying on existing digital materials allowed Klaus to assure a smooth course of the lesson and to realize relatively high levels of teaching quality.

\subsection{Patrick: An Example in Mathematics Teaching.}

A similar pattern emerged in the case of Patrick, a mathematics teacher with four years of teaching experience, but who described himself as a pragmatist who likes to integrate technologies. In the second week, he had low utility-value regarding technology integration. In the described lesson, he aimed at using a collaborative whiteboard app to collect and categorize linear equations and their transformations. Similar to Klaus, the learning activity did not work, as it resulted in large disturbances among students, which led him to conclude: "It was totally chaotic, as also students deleted correct solutions." (Patrick, entry week 2) 
Similar to Klaus' lesson, the instruction of the learning activity was likely not clear enough, and students would have needed more guidance while using the technology in the collaborative learning activities. Contrarily, in week 5, he used online learning material comprising simulations, video explanations, and adaptive exercises with online feedback from the GeoGebra Materials Platform, an international repository enabling teachers to use comprehensive interactive learning and teaching resources, which resulted in a lesson of high teaching quality: "The students discovered the proof of the theorem with the help of a GeoGebra book [dynamic geometry software]- perfect simulation and visualization of the processes of the theorem - and documented it on a worksheet." (Patrick, entry week 5)

This finding reflects the fact that high quality of technology integration requires teachers to thoroughly prepare their instruction. Additionally, the examples highlight that the use of content-specific material for their lessons may assist teachers to more thoroughly integrate technology and heighten teaching quality.

\subsection{Anna: An Example in English Teaching.}

Anna was an experienced English teacher with 21 years of teaching experience, describing herself as a pragmatist who likes to integrate technologies into her teaching. During the course of her teaching, the main theme was the textual analysis and interpretation of a specific narrative reading. In her first week, she reported high utility-value, which was also reflected in her lesson documentation: "Students explored the places where the protagonists live [with GoogleMaps Streetview], created screenshots, copied them into an Adobe Pages document and described the district in which the main characters live." (Anna, entry week 5)

Contrarily, in the following week, she perceived low utility-value. "Using the PDF Viewer, the students created a graph to describe the evolution of the relationship between two characters of the book." (Anna, entry week 6). In this lesson, Anna likely did not fully exploit 
the potential of educational technology, as she simply substituted analogous learning activities (i.e., drawing) by tablet-based activities. This finding suggest that besides general aspects of instructional quality, also the fit between topic and educational technology affected the perceived utility and the quality of technology integration.

The qualitative analysis show that it was easier for the example teachers to implement high teaching quality with technologies, if they used existing domain-specific applications. These applications already appropriately integrated the relevant pedagogy, content and affordances of the technology. Therefore, in these cases, the teachers were not faced with the challenge of integrating generic applications in a meaningful way into their domain-specific lesson procedure. More importantly, our qualitative analysis suggested that teachers' motivation and technology-enhanced teaching quality may be reciprocally dependent on each other. Therefore, it can be concluded that teacher motivation should not only be regarded as a source but also as the result of teachers' actions in the classroom.

\section{Discussion}

In the current study, we investigated the trajectories and relations of in-service teachers' motivation and technology integration by applying an experience sampling approach within daily classroom practice. Our findings showed that both motivation and technology integration were highly variable among documented lessons and therefore varied from situation to situation. Additionally, we found that part of the variability of the quality of technology integration was linked to individual differences of teachers' perceived utilityvalue of technology integration. Our qualitative analyses highlighted the reciprocal relationship between utility-value and technology integration, and their dependency on the instructional context in which technology was adopted. These different instructional contexts may have been responsible for the differences in motivation and technology integration.

\subsection{Motivation and Technology Integration are Context-Sensitive}


As a first contribution, we found that teachers' technology-related motivation varied across the lessons. Even though, approximately $30 \%$ of the motivation could be explained by stable traits, 60 - 70\% were determined by specific instructional contexts of the different lessons. Therefore, our findings contribute to general motivation research, which has emphasized the situated character of human motivation (Reeve, 2016), and extends the findings to professional domains such as teaching. In previous studies, self-efficacy remained rather stable across lessons, which could be due to the longer time period investigated (Holzberger et al., 2013; Praetorius et al., 2017). Therefore, the measures applied in those studies were more related to general teaching self-efficacy and not as context-sensitive as our measures which directly asked about the self-efficacy in the lessons during the specific documented week. However, these contradicting results should be further investigated in future studies.

Additionally, we found high variability in the quality of technology integration across lessons. In line with general research on teaching quality (Fauth et al., 2019; Praetorius et al., 2014) the study demonstrated that teaching quality is not a stable characteristic of teaching, but rather depends on individual contexts. The qualitative analyses further illustrated potential contextual variables that depend both on the teacher and their students, but also on the subject-matter and material used. When teachers relied on pre-given material which already implemented the specific potential of technologies in a meaningful way, they were more able to establish high teaching quality. This finding can be interpreted twofold: 1) teachers need more domain specific technology-enriched material, or 2) teachers need specific training to implement domain-general technologies into their distinct instructional context.

In sum, our findings highlight the need to investigate the circumstances and contexts which accounted for differences in teaching quality (Turner \& Meyer, 2000).

\subsection{Quality of Technology-Enhanced Teaching is Related to Utility-value}


The findings extend previous research on relations between teacher motivation and technology integration (e.g., Scherer et al., 2019), as despite the large variability in the key variables, perceived utility was significantly related to the quality of technology integration across lessons and contexts (see also Backfisch et al., 2020).

Self-efficacy did not account for the quality of technology integration and task-specific teaching quality, but only for the task-general teaching quality. However, based on expectancy-value theory, higher levels of self-efficacy should be important for the successful accomplishment of a task, such as the successful technology integration and therefore taskspecific teaching quality. Also Backfisch et al. (2020) did not find significant relations between self-efficacy and the quality of technology integration and proposed that self-efficacy may rather be important for the implementation of distinct technology, mostly indicated by the quantity of technology integration (see also Farjon, Smits, \& Voogt, 2019; Petko, 2012). For the quality of technology integration, utility-value might be more important, as perceived utility likely allows teachers to think about distinct potentials of technologies, which could result in higher exploitations of the technology. However, in the present study there was only a relationship between self-efficacy and task-general teaching quality and neither a relation of self-efficacy and frequency of technology integration nor quality of technology integration. Therefore, the direction and nature of the relationship is still an open question and should be addressed in further studies.

As a first hint, the qualitative analysis suggest that the relation of teacher motivation and technology integration is more of a reciprocal nature: If the perceived high utility, they integrated the technologies in a high qualitative manner (e.g, used technologies to heighten students' cognitive activation). Additionally, vice versa, if the teachers had positive experiences with technologies in the classroom, they perceived higher utility of educational technologies. Prospectively, the question should therefore be addressed whether this 
reciprocal mechanism holds true for larger teacher samples. It could also well be that a certain amount of general attitude towards the utility (as a trait component) is a necessary precondition for technology integration and a contextualized utility (as a state component) may depend on situational and concrete experiences during teaching with the technologies.

\subsection{Limitations and Future Research}

One central caveat refers to the fact that we realized a correlational design, which does not allow for investigating the causal effects of utility-value on technology integration (or vice versa). Therefore, based on our study, it is unclear whether utility-value would be a concurrent facet of successful technology integration, a causal factor determining the quality of technology integration, or whether utility-value is a consequence of high quality of technology integration. As a further development of our study, we would see to experimentally manipulate teachers' utility-value by inducing different levels of utility-value (see Brisson et al., 2017; Canning et al., 2018) to investigate whether utility-value would have a causal role in determining technology integration.

Additionally, we must admit, that we relied on teachers' documentations, and had no direct observations of technology integration, which may have affected our findings. Therefore, we see the need of replicating our findings in more contextualized settings, in which actual teaching behavior across multiple measurement points is analyzed, for instance by means of video-analyses.

\subsection{Conclusion}

To conclude, the present study helps to get a better understanding of teachers' motivational states which enable them to integrate technology across situations. Our findings indicate that their motivation and particularly current perceived utility-value of educational technologies play a critical role in integrating technology in a qualitatively high manner that largely depends on the particular context. From a teacher education perspective, teachers have 
to be aware of the influence of contextual aspects such as their motivation, as well as the quality and quantity of their technology integration. 


\section{References}

Aldrup, K., Klusmann, U., Lüdtke, O., Göllner, R., \& Trautwein, U. (2018). Social support and classroom management are related to secondary students' general school adjustment: A multilevel structural equation model using student and teacher ratings. Journal of Educational Psychology, 110(8), 1066. https://doi.org/10.1037/edu0000256

Backfisch, I., Lachner, A., Hische, C., Loose, F., \& Scheiter, K. (2020). Professional knowledge or motivation? Investigating the role of teachers' expertise on the quality of technology-enhanced lesson plans. Learning and Instruction, 66, 101300. https://doi.org/10.1016/j.learninstruc.2019.101300

Bandura, A. (2010). Self-efficacy. The Corsini Encyclopedia of Psychology, 1-3. https://doi.org/10.1002/9780470479216.corpsy0836

Bates, D., Maechler, M., Bolker, B., \& Walker, S. (2015). Fitting linear mixed-effects models using lme4. Journal of Statistical Software, 67(1), 1-48. https://doi.org/10.18637/jss.v067.i01

Baumert, J., Kunter, M., Blum, W., Brunner, M., Voss, T., Jordan, A., ... \& Tsai, Y.-M. (2010). Teachers' mathematical knowledge, cognitive activation in the classroom, and student progress. American Educational Research Journal, 47(1), 133-180. https://doi.org/10.3102/0002831209345157

Beauchamp, G., Burden, K., \& Abbinett, E. (2015). Teachers learning to use the iPad in Scotland and Wales: A new model of professional development. Journal of Education for Teaching, 41(2), 161-179. https://doi.org/10.1080/02607476.2015.1013370

Brisson, B. M., Dicke, A. L., Gaspard, H., Häfner, I., Flunger, B., Nagengast, B., \& Trautwein, U. (2017). Short intervention, sustained effects: Promoting students' math competence beliefs, effort, and achievement. American Educational Research Journal, 54(6), 1048-1078. https://doi.org/10.3102/0002831217716084 
Brophy, J. (1999). Toward a model of the value aspects of motivation in education:

Developing appreciation for.. Educational Psychologist, 34(2), 75-85. https://doi.org/10.1207/s15326985ep3402_1

Canning, E. A., Harackiewicz, J. M., Priniski, S. J., Hecht, C. A., Tibbetts, Y., \& Hyde, J. S. (2018). Improving performance and retention in introductory biology with a utility-value intervention. Journal of Educational Psychology, 110(6), 834.

https://doi.org/10.1037/edu0000244

Chauhan, S. (2017). A meta-analysis of the impact of technology on learning effectiveness of elementary students. Computers \& Education, 105, 14-30.

https://doi.org/10.1016/j.compedu.2016.11.005

Cheng, S. L., \& Xie, K. (2018). The relations among teacher value beliefs, personal characteristics, and TPACK in intervention and non-intervention settings. Teaching and Teacher Education, 74, 98-113. https://doi.org/10.1016/j.tate.2018.04.014

Cho, J. Y., \& Lee, E. H. (2014). Reducing confusion about grounded theory and qualitative content analysis: Similarities and differences. The Qualitative Report, 19(32), 1.

Danniels, E., Pyle, A., \& DeLuca, C. (2020). The role of technology in supporting classroom assessment in play-based kindergarten. Teaching and Teacher Education, 88, 102966. https://doi.org/10.1016/j.tate.2019.102966

Drossel, K., Eickelmann, B., \& Gerick, J. (2017). Predictors of teachers' use of ICT in school-the relevance of school characteristics, teachers' attitudes and teacher collaboration. Education and Information Technologies, 22, 551-573. https://doi.org/10.1007/s10639-016-9476-y

Duckworth, A. L., Tsukayama, E., \& May, H. (2010). Establishing causality using longitudinal hierarchical linear modeling: An illustration predicting achievement from self-control. Social Psychological and Personality Science, 1(4), 311-317. 
https://doi.org/10.1177/1948550609359707

Dukuzumuremyi, S., \& Siklander, P. (2018). Interactions between pupils and their teacher in collaborative and technology-enhanced learning settings in the inclusive classroom. Teaching and Teacher Education, 76, 165-174.

https://doi.org/10.1016/j.tate.2018.08.010

Eccles, J. S. (2005). Subjective task value and the Eccles et al. model of achievement-related choices. Handbook of Competence and Motivation, 105-121.

Eccles, J. S., \& Roeser, R. W. (2009). Schools, academic motivation, and stage-environment fit. Handbook of Adolescent Psychology, 1 . https://doi.org/10.1002/9780470479193.adlpsy001013

Eccles, J. S., \& Roeser, R. W. (2011). Schools as developmental contexts during adolescence. Journal of Research on Adolescence, 21(1), 225-241. https://doi.org/10.1111/j.1532$\underline{7795.2010 .00725 . x}$

Eccles, J. S., \& Wigfield, A. (2002). Motivational beliefs, values, and goals. Annual Review of Psychology, 53, 109-132. https://doi.org/10.1146/annurev.psych.53.100901.135153

Endberg, M. (2019). Professionswissen von Lehrpersonen der Sekundarstufe I zum Einsatz digitaler Medien im Unterricht: eine Untersuchung auf Basis einer repräsentativen Lehrerbefragung. [Professional knowledge of Secondary Teachers on the Use of Technology in the Classroom: A Study based on a Representative Teacher Survey.] Münster: Empirische Erziehungswissenschaft.

Endedijk, M. D., Brekelmans, M., Verloop, N., Sleegers, P. J., \& Vermunt, J. D. (2014). Individual differences in student teachers' self-regulated learning: An examination of regulation configurations in relation to conceptions of learning to teach. Learning and Individual Differences, 30, 155-162. https://doi.org/10.1016/j.lindif.2013.12.005

Farjon, D., Smits, A., \& Voogt, J. (2019). Technology integration of student teachers 
explained by attitudes and beliefs, competency, access, and experience. Computers \& Education, 130, 81-93. https://doi.org/10.1016/j.compedu.2018.11.010

Fauth, B., Decristan, J., Rieser, S., Klieme, E., \& Büttner, G. (2014). Student ratings of teaching quality in primary school: Dimensions and prediction of student outcomes. Learning and Instruction, 29, 1-9. http://dx.doi.org/10.1016/j.learninstruc.2013.07.001

Fauth, B., Wagner, W., Bertram, C., Göllner, R., Roloff, J., Lüdtke, O., Polikoff, M. S., Klusmann, U., \& Trautwein, U. (2019). Don't Blame the Teacher? The Need to Account for Classroom Characteristics in Evaluations of Teaching Quality. Journal of Educational Psychology. http://dx.doi.org/10.1037/edu0000416

Fraillon, J., Ainley, J., Schulz, W., Friedman, T., \& Duckworth, D. (2019). IEA international computer and information literacy Study 2018 assessment framework. Amsterdam: IEA.

Fraillon, J., Ainley, J., Schulz, W., Friedman, T., \& Gebhardt, E. (2014). Preparing for life in a digital age: The IEA international computer and information literacy study international report. Berlin: Springer. https://doi.org/10.1007/978-3-319-14222-7

Green, S. K. (2002). Using an expectancy-value approach to examine teachers' motivational strategies. Teaching and Teacher Education, 18, 989-1005. https://doi.org/10.1016/S0742-051X(02)00055-0

Hamilton, E. R., Rosenberg, J. M., \& Akcaoglu, M. (2016). The substitution augmentation modification redefinition (SAMR) model: a critical review and suggestions for its use. TechTrends, 60, 433-441. https://doi.org/10.1007/s11528-016-0091-y

Hamre, B. K., \& Pianta, R. C. (2007). Learning opportunities in preschool and early elementary classrooms. In R. C. Pianta, M. J. Cox, \& K. L. Snow (Eds.), School readiness and the transition to kindergarten in the era of accountability (p. 49-83). Baltimore: Paul H Brookes Publishing. 
Hidi, S., \& Harackiewicz, J. M. (2000). Motivating the academically unmotivated: A critical issue for the 21st century. Review of Educational Research, 70(2), 151-179. https://doi.org/10.3102/00346543070002151

Holzberger, D., Philipp, A., \& Kunter, M. (2013). How teachers' self-efficacy is related to instructional quality: A longitudinal analysis. Journal of Educational Psychology, 105(3), 774. https://doi.org/10.1037/a0032198

Hugener, I., Pauli, C., Reusser, K., Lipowsky, F., Rakoczy, K., \& Klieme, E. (2009). Teaching patterns and learning quality in Swiss and German mathematics lessons. Learning and Instruction, 19, 66-78. https://doi.org/10.1016/j.learninstruc.2008.02.001

Hughes, J., Thomas, R., \& Scharber, C. (2006). Assessing technology integration: The RATreplacement, amplification, and transformation-framework. Society for Information Technology \& Teacher Education International Conference, 1616-1620. Association for the Advancement of Computing in Education (AACE)

Ifenthaler, D., \& Schweinbenz, V. (2013). The acceptance of tablet-pcs in classroom instruction: The teachers' perspectives. Computers in Human Behavior, 29(3), 525-534. https://doi.org/10.1016/j.chb.2012.11.004

Könings, K. D., van Berlo, J., Koopmans, R., Hoogland, H., Spanjers, I. A., ten Haaf, J. A., ... \& van Merriënboer, J. J. (2016). Using a smartphone app and coaching group sessions to promote residents' reflection in the workplace. Academic Medicine, 91(3), 365-370. https://doi.org/10.1097/ACM.0000000000000989

Koo, T. K., \& Li, M. Y. (2016). A guideline of selecting and reporting intraclass correlation coefficients for reliability research. Journal of Chiropractic Medicine, 15(2), 155-163. https://doi.org/10.1016/j.jcm.2016.02.012 
Kounin, J. S. (1970). Discipline and group management in classrooms. New York: Holt, Rinehart \& Winston.

Kramarski, B., \& Michalsky, T. (2010). Preparing preservice teachers for self-regulated learning in the context of technological pedagogical content knowledge. Learning and Instruction, 20, 434-447. https://doi.org/10.1016/j.learninstruc.2009.05.003

Krauskopf, K., Zahn, C., \& Hesse, F. W. (2012). Leveraging the affordances of Youtube: The role of pedagogical knowledge and mental models of technology functions for lesson planning with technology. Computers \& Education, 58(4), 1194-1206.

https://doi.org/10.1016/j.compedu.2011.12.010

Kunter, M., Klusmann, U., Baumert, J., Richter, D., Voss, T., \& Hachfeld, A. (2013). Professional competence of teachers: Effects on instructional quality and student development. Journal of Educational Psychology, 105(3), 805-820. https://doi.org/10.1037/a0032583

Lachner, A., Backfisch, I., \& Stürmer, K. (2019). A test-based approach of modeling and measuring technological pedagogical knowledge. Computers \& Education, 142, 103645. https://doi.org/10.1016/j.compedu.2019.103645

Lachner, A., Burkhart, C., \& Nückles, M. (2017). Mind the gap! Automated concept map feedback supports students in writing cohesive explanations. Journal of Experimental Psychology: Applied, 23(1), 29. https://doi.org/10.1037/xap0000111

Ma, W., Adesope, O. O., Nesbit, J. C., \& Liu, Q. (2014). Intelligent tutoring systems and learning outcomes: A meta-analysis. Journal of Educational Psychology, 106(4), 901. https://doi.org/10.1037/a0037123

Mantzicopoulos, P., French, B. F., Patrick, H., Watson, J. S., \& Ahn, I. (2018). The stability of kindergarten teachers' effectiveness: a generalizability study comparing the framework for teaching and the classroom assessment scoring system. Educational 
Assessment, 23(1), 24-46. https://doi.org/10.1080/10627197.2017.1408407

Mayer, R. E. (2019). Computer games in education. Annual Review of Psychology, 70. https://doi.org/10.1146/annurev-psych-010418-102744

Mayring, P. (2015). Qualitative Inhaltsanalyse. [Qualitative Content Analysis]. 12th edition. Weinheim, Basel: Betlz

McCrudden, M. T., Marchand, G., \& Schutz, P. (2019). Mixed methods in educational psychology inquiry. Contemporary Educational Psychology, 57, 1-8. https://doi.org/10.1016/j.cedpsych.2019.01.008

Mishra, P., \& Koehler, M. J. (2006). Technological pedagogical content knowledge: A framework for integrating technology in teacher knowledge. Teachers College Record, 108(6), 1017-1054.

Moore, C. (2016). gtheory: Apply Generalizability Theory with R. R package version 0.1.2. https://CRAN.R-project.org/package=gtheory

Moreno, R., \& Mayer, R. (2007). Interactive multimodal learning environments. Educational Psychology Review, 19(3), 309-326. https://doi.org/10.1007/s10648-007-9047-2

Näykki, P., \& Järvelä, S. (2008). How pictorial knowledge representations mediate collaborative knowledge construction in groups. Journal of Research on Technology in Education, 40(3), 359-387. https://doi.org/10.1080/15391523.2008.10782512

OECD. (2015). Students, computers and learning: Making the connection. PISA, OECD Publishing. https://dx.doi.org/10.1787/9789264239555-en

Paratore, J. R., O’Brien, L. M., Jimenez, L., Salinas, A., \& Ly, C. (2016). Engaging preservice teachers in integrated study and use of educational media and technology in teaching reading. Teaching and Teacher Education, 59, 247-260.

https://doi.org/10.1016/j.tate.2016.06.003 
Petko, D. (2012). Teachers' pedagogical beliefs and their use of digital media in classrooms: Sharpening the focus of the "will, skill, tool" model and integrating teachers" constructivist orientations. Computers \& Education, 58, 1351-1359. https://doi.org/10.1016/j.compedu.2011.12.013

Pianta, R. C., \& Hamre, B. K. (2009). Conceptualization, measurement, and improvement of classroom processes: Standardized observation can leverage capacity. Educational Researcher, 38(2), 109-119. https://doi.org/10.3102/0013189X09332374

Praetorius, A. K., Klieme, E., Herbert, B., \& Pinger, P. (2018). Generic dimensions of teaching quality: the German framework of Three Basic Dimensions. ZDM, 50(3), 407426. https://doi.org/10.1007/s11858-018-0918-4

Praetorius, A. K., Lauermann, F., Klassen, R. M., Dickhäuser, O., Janke, S., \& Dresel, M. (2017). Longitudinal relations between teaching-related motivations and student-reported teaching quality. Teaching and Teacher Education, 65, 241-254. https://doi.org/10.1016/j.tate.2017.03.023

Praetorius, A. K., Lenske, G., \& Helmke, A. (2012). Observer ratings of instructional quality: Do they fulfill what they promise? Learning and Instruction, 22(6), 387-400. https://doi.org/10.1016/j.learninstruc.2012.03.002

Praetorius, A. K., Pauli, C., Reusser, K., Rakoczy, K., \& Klieme, E. (2014). One lesson is all you need? Stability of instructional quality across lessons. Learning and Instruction, 31, 2-12. https://doi.org/10.1016/j.learninstruc.2012.03.002

Praetorius, A. K., Vieluf, S., Saß, S., Bernholt, A., \& Klieme, E. (2016). The same in German as in English? Investigating the subject-specificity of teaching quality. Zeitschrift für Erziehungswissenschaft, 19(1), 191-209. https://doi.org/10.1007/s11618-015-0660-4

Puentedura, R. (2006). Transformation, technology, and education [Blog post]. Retrieved from http://hippasus.com/resources/tte/. 
Questback GmbH. (2017). EFS Survey, Version Summer 2017. Köln: Questback $\mathrm{GmbH}$.

R Core Team (2019). R: A language and environment for statistical computing. R Foundation for Statistical Computing, Vienna, Austria. https://www.R-project.org/.

Reeve, J. (2016). A grand theory of motivation: Why not? Motivation and Emotion, 40(1),

31-35. https://doi.org/10.1007/s11031-015-9538-2

Renkl, A., \& Scheiter, K. (2017). Studying visual displays: How to instructionally support learning. Educational Psychology Review, 29(3), 599-621. https://doi.org/10.1007/s10648-015-9340-4

Rigotti, T., Schyns, B., \& Mohr, G. (2008). A short version of the occupational self-efficacy scale: Structural and construct validity across five countries. Journal of Career Assessment, 16(2), 238-255. https://doi.org/10.1177/1069072707305763

Sang, G., Valcke, M., van Braak, J., \& Tondeur, J. (2010). Student teachers’ thinking processes and ICT integration: Predictors of prospective teaching behaviors with educational technology. Computers \& Education, 54, 103-112. https://doi.org/10.1016/j.compedu.2009.07.010

Scherer, R., Siddiq, F., \& Tondeur, J. (2019). The technology acceptance model (TAM): A meta-analytic structural equation modeling approach to explaining teachers' adoption of digital technology in education. Computers \& Education, 128, 13-35. https://doi.org/10.1016/j.compedu.2018.09.009

Scherer, R., \& Teo, T. (2019). Unpacking teachers' intentions to integrate technology: A meta-analysis. Educational Research Review. https://doi.org/10.1016/j.edurev.2019.03.001

Schmitt, L. J., \& Weinberger, A. (2018). Computer-Supported Collaborative Learning: Mediated and Co-Present Forms of Learning Together. Second Handbook of Information 
Technology in Primary and Secondary Education, 217-231.

Seidel, T., \& Prenzel, M. (2006). Stability of teaching patterns in physics instruction:

Findings from a video study. Learning and Instruction, 16(3), 228-240.

https://doi.org/10.1016/j.learninstruc.2006.03.002

Sung, Y. T., Yang, J. M., \& Lee, H. Y. (2017). The effects of mobile-computer-supported collaborative learning: Meta-analysis and critical synthesis. Review of Educational Research, 87(4), 768-805. https://doi.org/10.3102/0034654317704307

Taimalu, M., \& Luik, P. (2019). The impact of beliefs and knowledge on the integration of technology among teacher educators: A path analysis. Teaching and Teacher Education, 79, 101-110. https://doi.org/10.1016/j.tate.2018.12.012

Teo, T. (2011). Factors influencing teachers' intention to use technology: Model development and test. Computers \& Education, 57(4), 2432-2440. https://doi.org/10.1016/j.compedu.2011.06.008

Teo, T., Huang, F., \& Hoi, C. K. W. (2018). Explicating the influences that explain intention to use technology among English teachers in China. Interactive Learning Environments, 26, 460-475. https://doi.org/10.1080/10494820.2017.1341940

Turner, J. C., \& Meyer, D. K. (2000). Studying and understanding the instructional contexts of classrooms: Using our past to forge our future. Educational Psychologist, 35(2), 6985. https://doi.org/10.1207/S15326985EP3502_2

U.S Department of Education. (2020). Reimagining the Role of Technology in Education. National Educational Technology Plan.

van Braak, J., Tondeur, J., \& Valcke, M. (2004). Explaining different types of computer use among primary school teachers. European Journal of Psychology of Education, 19, 407422. https://doi.org/10.1007/BF03173218

van de Pol, J., Volman, M., Oort, F., \& Beishuizen, J. (2015). The effects of scaffolding in the 
classroom: support contingency and student independent working time in relation to student achievement, task effort and appreciation of support. Instructional Science, 43(5), 615-641. https://doi.org/10.1007/s11251-015-9351-z

Vongkulluksn, V. W., Xie, K., \& Bowman, M. A. (2018). The role of value on teachers' internalization of external barriers and externalization of personal beliefs for classroom technology integration. Computers \& Education, 118, 70-81. https://doi.org/10.1016/j.compedu.2017.11.009

Wagner, W., Göllner, R., Werth, S., Voss, T., Schmitz, B., \& Trautwein, U. (2016). Student and teacher ratings of instructional quality: Consistency of ratings over time, agreement, and predictive power. Journal of Educational Psychology, 108(5), 705-721. $\underline{\text { https://doi.org/10.1037/edu0000075 }}$

Wäschle, K., Allgaier, A., Lachner, A., Fink, S., \& Nückles, M. (2014). Procrastination and self-efficacy: Tracing vicious and virtuous circles in self-regulated learning. Learning and Instruction, 29, 103-114. https://doi.org/10.1016/j.learninstruc.2013.09.005

White, A. M., DeCuir-Gunby, J. T., \& Kim, S. (2019). A mixed methods exploration of the relationships between the racial identity, science identity, science self-efficacy, and science achievement of African American students at HBCUs. Contemporary Educational Psychology, 57, 54-71. https://doi.org/10.1016/j.cedpsych.2018.11.006

Wirtz, M. A., \& Caspar, F. (2002). Beurteilerübereinstimmung und Beurteilerreliabilität: Methoden zur Bestimmung und Verbesserung der Zuverlässigkeit von Einschätzungen mittels Kategoriensystemen und Ratingskalen [Inter-rater agreement and inter-rater reliability: Methods for calculating and improving the reliability of ratings by category systems and rating scales]. Göttingen: Hogrefe.

Wozney, L., Venkatesh, V., \& Abrami, P. (2006). Implementing computer technologies: Teachers' perceptions and practices. Journal of Technology and Teacher Education, 
14(1), 173-207.

Zhu, C., \& Urhahne, D. (2018). The use of learner response systems in the classroom enhances teachers' judgment accuracy. Learning and Instruction, 58, 255-262. http://dx.doi.org/10.1016/j.learninstruc.2018.07.011 
Figures

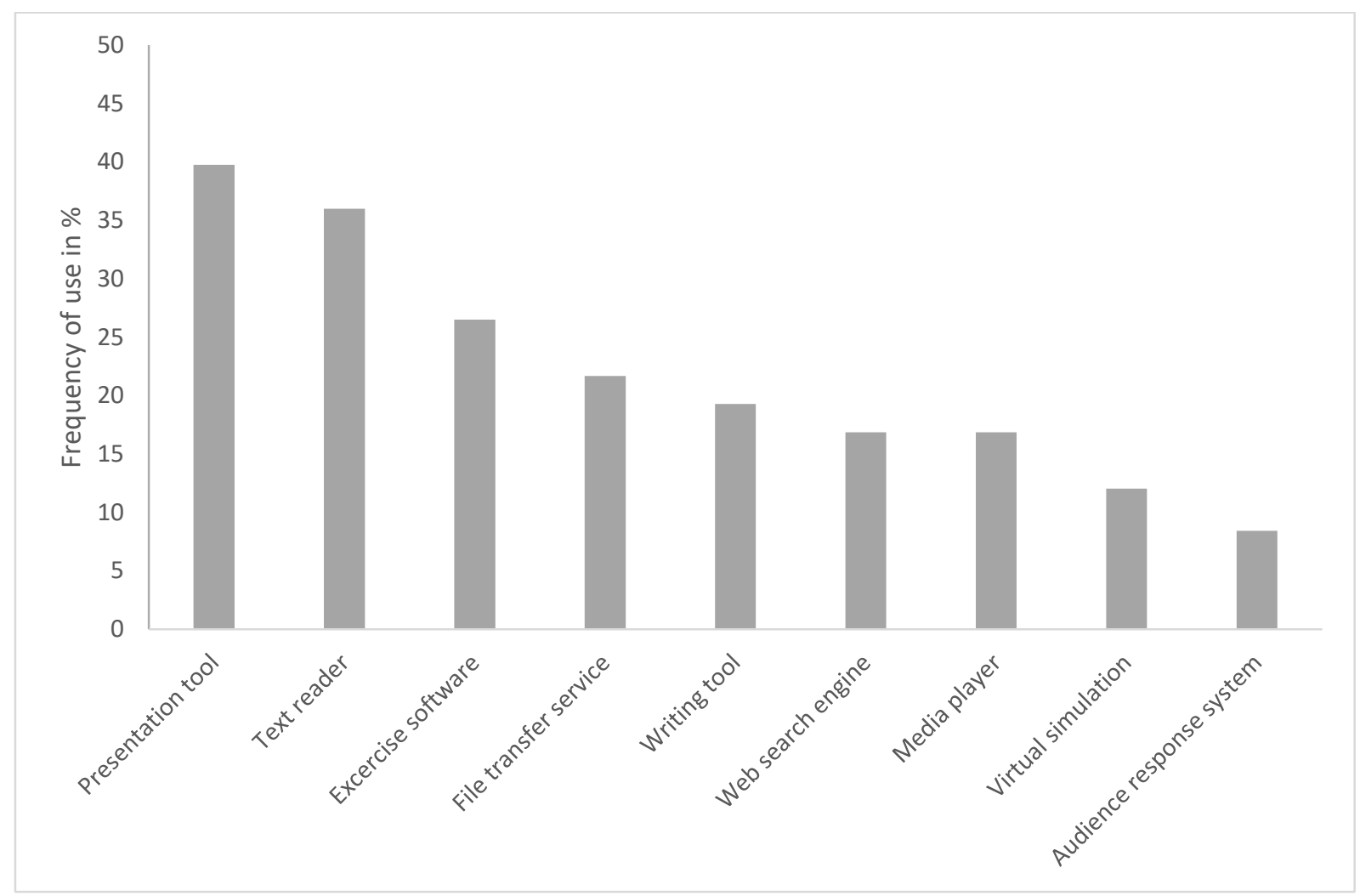

Figure 1. Type of used technologies within the documented lessons. Bar charts represent the frequency of use per teacher. 
Self-efficacy

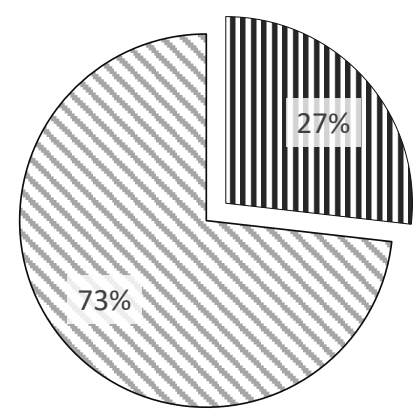

Utility-value

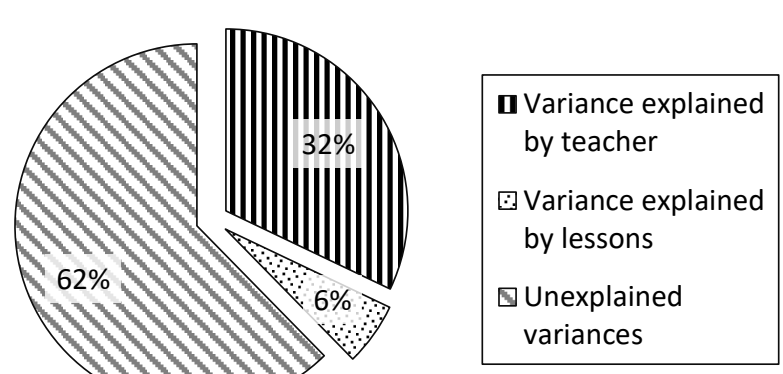

Figure 2. Variance component analysis for teachers' self-efficacy (left) and utility value (right). 
Frequency of technology integration

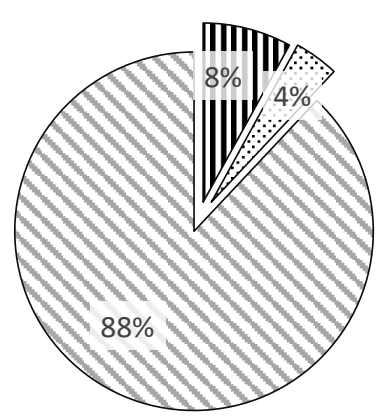

Task-specific teaching quality

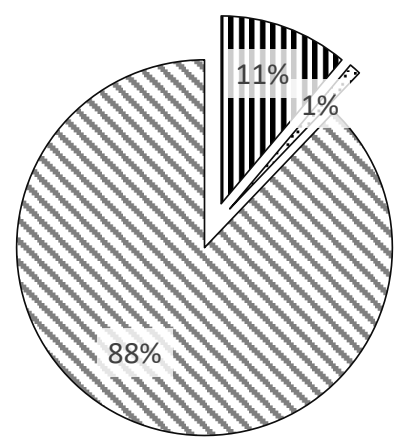

Level of technology exploitation

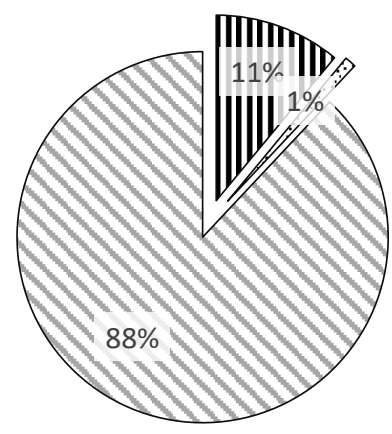

U Variance explained by teacher

Variance explained by lessons

$\checkmark$ Unexplained variances

Figure 3. Variance component analysis for the frequency of technology integration (upper left), level of technology exploitation (upper right), task-specific teaching quality (lower left), and task-general teaching quality (lower right). 


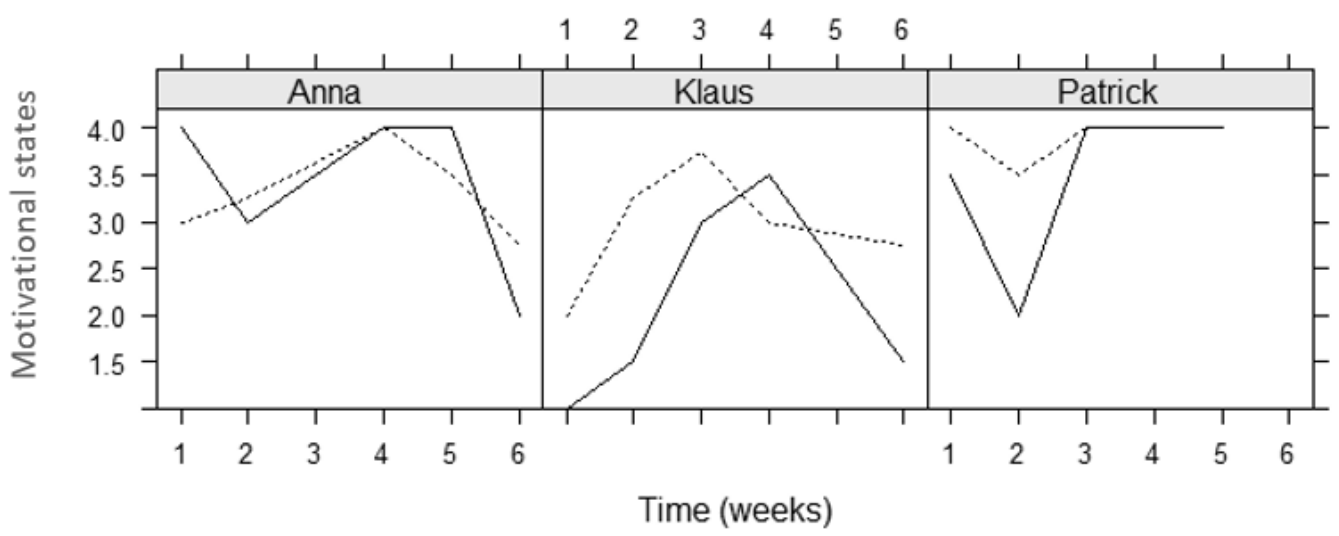

Figure 4. Plots of individual trajectories of perceived utility value (solid line) and selfefficacy (dotted line) of the exemplary teachers of the qualitative analysis. Utility value and self-efficacy was rated on a 4-point Likert scale per week (x-axis) across six weeks (y-axis). 


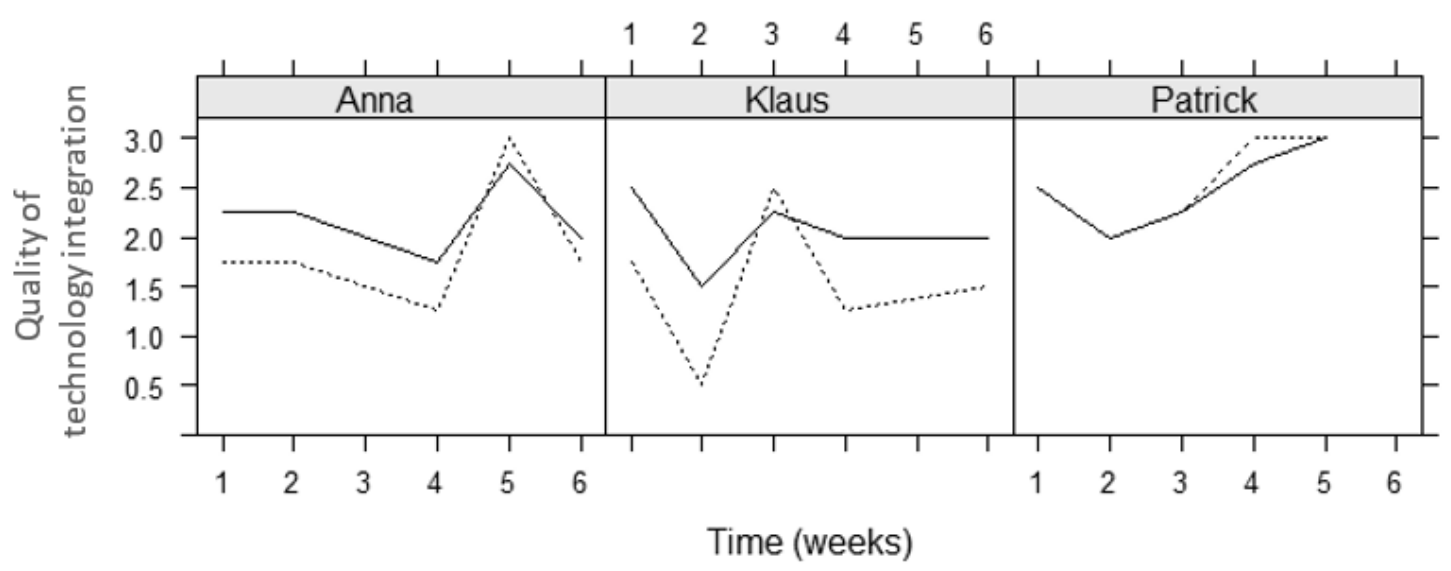

Figure 5. Plots of individual trajectories of the quality of technology integration (i.e., taskspecific teaching quality (solid line) and technology exploitation (dotted line)) of the exemplary teachers of the qualitative analysis. Task-specific teaching quality and technology exploitation was rated on a 0 to 3 scale each week across six weeks (y-axis). 


\section{Tables}

\section{Table 1}

Coding Scheme for Quality of Technology Integration

\begin{tabular}{ll}
\hline Subcategories & \multicolumn{1}{l}{ Description } \\
\hline $\begin{array}{l}\text { Task-specific teaching quality } \\
\text { Provision of } \\
\text { cognitively } \\
\text { challenging } \\
\text { activities }\end{array}$ & $\begin{array}{l}\text { Teacher provided students with } \\
\text { tasks which they have to think } \\
\text { about thoughtfully. }\end{array}$ \\
& \\
$\begin{array}{l}\text { Support of } \\
\text { students' } \\
\text { knowledge } \\
\text { construction }\end{array}$ & $\begin{array}{l}\text { Teacher supported students' } \\
\text { discovery of overall context of } \\
\text { the lesson topics. }\end{array}$ \\
$\begin{array}{l}\text { Encouragement of } \\
\text { students' } \\
\text { participation }\end{array}$ & $\begin{array}{l}\text { Teacher encouraged students to } \\
\text { explain connections of different } \\
\text { concepts, ideas and }\end{array}$ \\
$\begin{array}{l}\text { Provision of } \\
\text { instructional } \\
\text { guidance }\end{array}$ & $\begin{array}{l}\text { Teacher provided instructional } \\
\text { guidance to enhance students' } \\
\text { learning processes. }\end{array}$
\end{tabular}

Examples (excerpts of lesson documentations)

Students had to search on a screenshot of the map of our city (provided in Geogebra) for the point with exactly the same distances from the houses of three students to explore the circumference of a triangle as the intersection of the two perpendicular bisectors. (mathematics lesson)

The students independently explored the differences between Protestant, Calvinist and Catholic dogma and summarized the results in a digital mind map. (history lesson)

Students watch an explanation video on relative clauses and had to write down the rules on their own and we discussed this. (EFL lesson)

Students added information to a pre-structured timeline and received additional information via airdrop if they did not know how to continue. (history lesson)

\section{Technology exploitation}

Innovativeness of technology adoption

Application of adaptivity

Application of multimodality

Application of interactivity
The technologies are used to make the course of the lesson more effective and enable a new way of teaching.

The technologies are used to adapt the content on students' knowledge (e.g., based on technology-based formative assessment).

The technologies are used to present multiple forms of representation (e.g., video, audio, pictures).

The technologies are used to heighten students' communication and collaboration.
Students worked on an interactive working sheet with hyperlinks to explanation videos and virtual simulations which they could look at if they had troubles. (mathematics lesson)

Students used learningapps.org to practice and received automatically feedback and additional information if they did a mistake. (EFL lesson)

Students had to invent a story to a given graph and had to record an audio or video message about the story. (mathematics lesson)

Students worked simultaneously on an overview of the topic in one live-synchronized document and discussed the information provided by others with the chat application. (Latin lesson) 
Table 2

Means and Standard Deviations of the Variables Across Lessons

SD

Motivation $^{\mathrm{a}}$

Self-efficacy

3.25

.703

Utility value

2.94

.881

Quantity of technology integration

Frequency of technology use ${ }^{b}$

76.97

32.851

Quality of lessons

Technology exploitation ${ }^{c}$

1.92

.678

Task-general teaching quality ${ }^{d}$

4.10

.993

Task-specific teaching quality ${ }^{\mathrm{c}}$

2.15

.443

${ }^{a}$ Teacher ratings ranged from 1 (strongly disagree) to 4 (strongly agree), ${ }^{\mathrm{b}}$ Values represent percentage scores, ${ }^{c}$ Values represent means of the rating 0 (subcategory not applied) to 3 (subcategory ubiquitous applied), ${ }^{d}$ Values represent means of the rating from 1 (does not apply) to 5 (does apply). 
Table 3

Bivariate Correlations of the Mean of the Investigated Variables across all Entries

1

2

3

4

5

1 Self-efficacy beliefs

2 Utility value

$.677^{\star *}$

3 Frequency of technology integration

.190

$.282^{* *}$

4 Technology exploitation

.203

$.400^{\star *}$

.173

5 Task-general teaching quality

$.486^{* *} \quad .520^{* *} \quad .195 \quad .031$

6 Task-specific teaching quality

.181

$.275^{\star}$

.104

$.848^{* *}$

.037

Note. ${ }^{*} p<.05 .{ }^{* *} p<.001$. 